Article

\title{
Effects of Additives and Metals on Crystallization of Nano-Sized HZSM-5 Zeolite for Glycerol Aromatization
}

\author{
Wei Xu ${ }^{1,2,3}$, Lijing Gao ${ }^{3, *}$ and Guomin Xiao ${ }^{3}$ \\ 1 School of Environmental Engineering, Nanjing Institute of Technology, Nanjing 211167, China; \\ xuwei@njit.edu.cn \\ 2 Energy Research Institute, Nanjing Institute of Technology, Nanjing 211167, China \\ 3 School of Chemistry and Chemical Engineering, Southeast University, Nanjing 211189, China; \\ xiaogm@seu.edu.cn \\ * Correspondence: gaolj@seu.edu.cn; Tel.: +86-25-52090612
}

Received: 10 October 2019; Accepted: 26 October 2019; Published: 28 October 2019

\begin{abstract}
Nano-sized HZSM-5 (n-HZSM-5) was synthesized and applied in the aromatization of glycerol. The effects of additives (carboxymethylcellulose sodium, $\mathrm{NaCl}$, sodium alginate, etc.) on the chemical and physic properties of n-HZSM-5 during preparation were investigated. Metal modification was also investigated based on the synthesized n-HZSM-5. The results showed that the addition of carboxymethylcellulose sodium (CMC-Na), $\mathrm{NaCl}$ and sodium alginate (SA) led to forming smaller sizes of HZSM-5 and promoted the acid amounts of the catalysts, which increased its catalytic activities for obtaining BTX. The highest BTX yield of $\sim 35 \%$ was obtained by SA derived n-HZSM-5, and the life of the catalyst were both obviously promoted by the additives with a highest of $\sim 11 \mathrm{~h}$ by $\gamma$-(2,3-epoxypropoxy)propytrimethoxysilane (KH-560) derived n-HZSM-5. BTX yields could be improved by $40 \%$ by the addition of $\mathrm{Zn}$ and $\mathrm{Cd}$ in $\mathrm{n}-\mathrm{HZSM}-5$ while having little effect on the catalyst life.
\end{abstract}

Keywords: nano-sized HZSM-5; glycerol; aromatization; BTX

\section{Introduction}

As a major by-product of biodiesel, the effective use of glycerol can promote the development of the biodiesel industry [1]. Due to its chemical and physical properties, purification of crude glycerol is extremely diseconomy, which makes it mostly treated as an industrial waste [2,3]. Thus, the utilization of glycerol is important for the economic aspect as well as the environmental ones [4,5].

Conversion of glycerol to hydrocarbons, especially benzene, toluene and xylene (BTX) seems to be a promising way for its rational use and has attracted much concerns $[6,7]$. The catalytic process for glycerol to aromatics can usually be considered as a derivative of methanol or olefins to aromatics [8], which includes numerous steps such as dehydrogenation, dehydration, hydrogenolysis, deoxygenation, cracking, hydrogenation, oligomerization, and cyclization $[9,10]$. All these reactions could be catalyzed by Brønst or Lewis acid. HZSM-5, which is made by ammonium ion exchange of Na-ZSM-5, still has its unique 3D Crisscrossed-tunnel structure system. The diameter of the linear channels is about $5.3 \times 5.6 \AA$ and the diameter of the sinoidal channels is about $5.1 \times 5.5 \AA$ [11]. These pore sizes are similar to the kinetic diameter of xylene, which only allow molecules with a size not exceeding tetramethylbenzene to pass. Thus, HZSM-5 has a good shape selectivity of aromatic rings [12]. At the same time, the surface of HZSM-5 has various acidic sites including Brønst and Lewis acid, which can catalyze multiple steps in the aromatization reaction, and the researchers can use various methods to change the acidity of HZSM- 5 catalysts by adjusting the kinds, strength and amount of the acid 
sites. Thus, Catalysts based on HZSM-5 have so far been found to be the most effective catalyst for the aromatization of glycerol [13]. Metals such as $\mathrm{Zn}$ [14], Sn [15] and $\mathrm{Cu}$ [16] modified HZSM-5 would improve the selectivity of aromatics to $25 \sim 30 \%$ with a glycerol conversion of $\sim 100 \%$. However, the catalytic performance, especially the stability is still far for industrial use. A aromatics yield of $20.9 \%$ with only a lifetime of $3 \mathrm{~h}$ were obtained by Hoang et.al [13] for pure glycerol over bare HZSM-5. It is believed that the coke formation cause by the sole micropores, which seriously restricts the diffusion of coke precursors lead to the coverage of the active sites and the deactivation of the catalyst. On another hand, the density and distribution of acid sites was also found to be related to the coke deposition [17-19]. Therefore, it is generally believed that adjusting the strength and distribution of the HZSM- 5 acid sites can enhance lifetime in the glycerol aromatization process.

Another way to prolong the catalysts life is changing the pore properties of HZSM- 5 for overcoming the diffusion limitations and reducing coking. Research [20,21] showed hierarchical porous ZSM-5 zeolite, which facilitates the diffusion and increases the capacity of coke with its mesopores, maintains high selectivity for aromatics by micropores simultaneously. A desilication process with alkali is commonly used for the synthesis of hierarchical ZSM-5, which can also adjust the acidity properties [22]. As the density and distribution of acid sites was also found to be related to the coke deposition [17-19], adjusting them was believed to be beneficial to reduce coking. It is demonstrated that nano-zeolites with grain sizes that are less than $100 \mathrm{~nm}$ can also solve the diffusion problems besides the hierarchical porous structure. Hoang et.al [23] found that smaller crystallite presented slower deactivation for the aromatization of propanal. Good catalytic and diffusion performance of nanocrystallite ZSM- 5 was also reported by Jia et.al [24] and Yang et.al [25] for methanol to aromatics, but there still is a lack of studies on the effect of catalyst size, especially nanocrystllite HZSM-5, on glycerin to aromatics. Alkali metal salts, polymers, etc. have been used for the synthesis of nano-sized zeolites as additives [26]. Studies $[27,28]$ showed that the ions in metal salts mainly affect the nucleation process while the three-dimensional network or hydroxyl groups mainly play roles in controlling zeolite growth rate and preventing the agglomeration.

In this work, in order to prolong the catalysts life in glycerin aromatization, n-HZSM-5 was introduced to solve diffusion problems and reduce coking. All studied n-HZSM- 5 was prepared by introducing different additives in the synthesis gel, which including metal salt and polymer hydrogel. The effects of the additives on zeolites' chemical and physic properties as well as the catalytic performance were investigated. A relation between additives, catalyst structure, catalytic activity and life was expected.

\section{Results and Discussion}

\subsection{Effects of Additives}

\subsubsection{Characterization of the n-HZSM-5 Catalysts}

The X-ray diffraction (XRD) patterns of the catalyst synthesized with different additives are presented in Figure 1. As shown in this figure, all the samples have the diffractions in $2 \theta$ range of $1 \sim 10^{\circ}$ and 22.5 25 $5^{\circ}$, which were attributed to the characteristic diffraction of HZSM-5 [29]. Compared with commercial HZSM-5, a single phase was presented, indicating that the synthesized catalyst was pure HZSM- 5 and crystallized quite well. The crystallinity was calculated by the ratio of the diffraction area $\left(2 \theta=22.5 \sim 25^{\circ}\right)$ according to ASTM D5758-01 and the results are shown in Table 1 . It can be seen from Table 1 that the addition of $\mathrm{NaCl}$, PEG-10000 and KH-560 led to the decrease of crystallinity, while CMC-Na and SA have less effect on the crystallinity of HZSM-5. Indicating that the additives used could more or less influence the nucleation and crystallization process besides CMC-Na and SA.

The TEM images of the catalysts are shown in Figure 2. It can be seen from this figure that the common HZSM-5 presented a rectangular shape with crystalline size of 200 300 nm. With the addition of CMC-Na (HZSM-5-C), NaCl (HZSM-5-N) or SA(HZSM-5-S), the crystalline size decreased to less than $100 \mathrm{~nm}$. The reason why $\mathrm{NaCl}$ reduced the crystal size could be that $\mathrm{Na}^{+}$and $\mathrm{Cl}^{-}$might adhered 
to the surface of the particle and played a role as dispersants, which restrained their growth and agglomeration. In addition, $\mathrm{Na}^{+}$could also play a role of cation template similar as $\mathrm{TPA}^{+}$, which would accelerate the nucleation and lead a smaller crystal. CMC-Na and SA contributed a polymer hydrogel system, which allowed ZSM- 5 crystallized in a three-dimensional network of the cross-linked structure to obtain small crystals [28,30,31]. However, the crystalline size had little change and even increased with the addition of PEG-10000 (HZSM-5-P) and KH-560 (HZSM-5-K). HZSM-5-K specially presented a crystalline size about $400 \mathrm{~nm}$ with an ellipse shape. Magnified images of them showed bright point on the crystalline particles, indication the presence of mesoporous in the crystalline particle of HZSM-5-P and HZSM-5-K. It can be conclude that NaCl, CMC-Na and SA led to the n-HZSM-5 while PEG-10000 and KH-560 facilitated the formation of hierarchical pores.

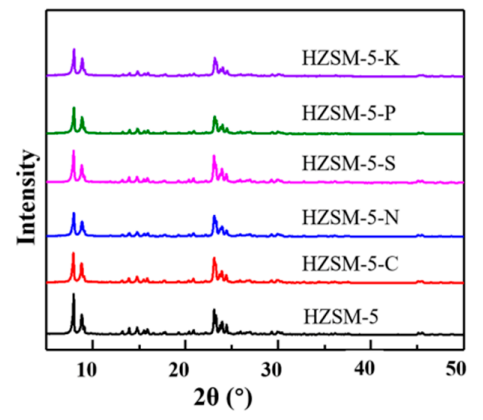

Figure 1. XRD patterns of the synthesized HZSM-5 zeolites.

Table 1. Crystallinity of HZSM-5 synthesized with different additives.

\begin{tabular}{cccccc}
\hline Samples & HZSM-5-C & HZSM-5-N & HZSM-5-S & HZSM-5-P & HZSM-5-K \\
\hline Crystallinity ${ }^{\text {a } \%}$ & 100.1 & 90.9 & 103.1 & 79.1 & 83.6 \\
\hline \multicolumn{5}{c}{${ }^{a}$ Relatively crystallinity compared with commercial HZSM-5 (100\%). }
\end{tabular}

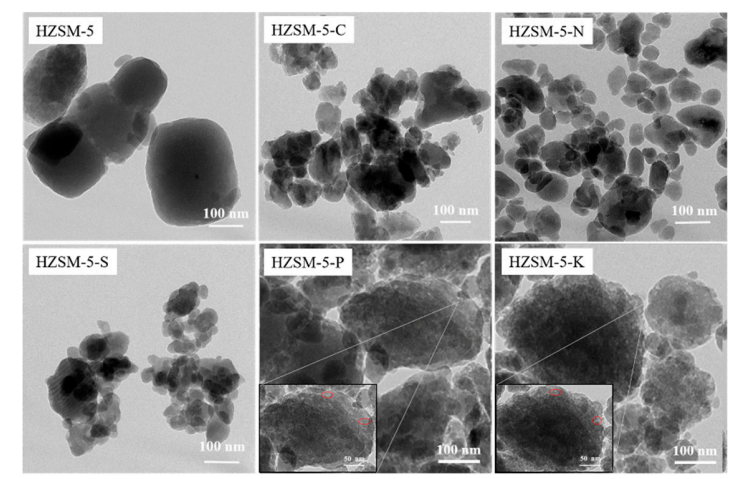

Figure 2. TEM images of the synthesized HZSM-5 zeolites.

Figure 3 showed the $\mathrm{N}_{2}$ adsorption-desorption isotherms of the catalysts. It can be seen that all of the HZSM-5 synthesized with additives exhibited hysteresis loops at $\mathrm{P} / \mathrm{P}_{0}=0.85 \sim 1.0$ compared with common HZSM-5, which might be caused by the intergranular mesoporous or inter mesopores generated by the agglomeration of nanocrystals. This coincided with the TEM results. The detailed textural properties of the catalysts are listed in Table 2. It can be seen that the participation of additives in crystallation all led to the increase of specific surface area. Compared with HZSM-5, the volume of microporous almost remained constant, while the volume of mesoporous increased except for HZSM-5-C. The agglomeration of nano-crystals, which is shown in Figure 2, might have led to the decrease of mesoporous as well as the extra specific surface area. It was also shown that the HZSM-5-P and HZSM-5-K presented an obviously incensement in mesoporous. Combined with the TEM characterization, this might be attributed to the mesoporous in the crystalline particle. 


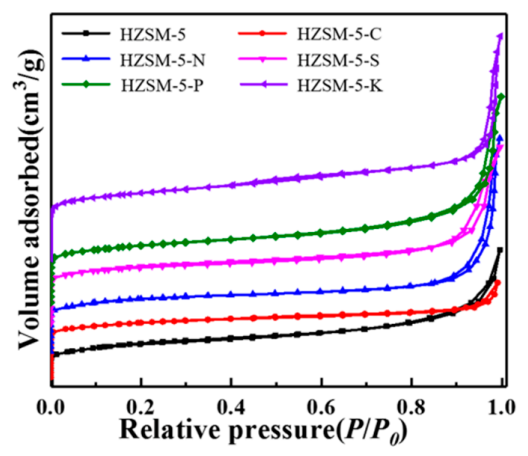

Figure 3. $\mathrm{N}_{2}$ adsorption-desorption isotherms of the synthesized HZSM-5 zeolites.

Table 2. Physical properties of HZSM-5 synthesized with different additives.

\begin{tabular}{cccccc}
\hline Catalysts & $\left.\mathbf{S}_{\text {BET }}{ }^{\mathbf{a}} \mathbf{( m}^{\mathbf{2}} \mathbf{g}\right)$ & $\mathbf{S}_{\text {micro }}{ }^{\mathbf{b}}\left(\mathbf{m}^{\mathbf{2}} / \mathbf{g}\right)$ & $\mathbf{V}_{\text {total }}(\mathbf{m L} / \mathbf{g})$ & $\mathbf{V}_{\text {micro }} \mathbf{b}^{(\mathbf{m L} / \mathbf{g})}$ & $\mathbf{V}_{\text {meso }}{ }^{\mathbf{c}}(\mathbf{m L} / \mathbf{g})$ \\
\hline HZSM-5 & 375.5 & 207.5 & 0.49 & 0.11 & 0.38 \\
HZSM-5-C & 379.2 & 225.8 & 0.31 & 0.12 & 0.18 \\
HZSM-5-N & 385.8 & 202.4 & 0.53 & 0.11 & 0.39 \\
HZSM-5-S & 400.0 & 199.0 & 0.57 & 0.11 & 0.45 \\
HZSM-5-P & 408.4 & 216.1 & 0.67 & 0.11 & 0.55 \\
HZSM-5-K & 468.6 & 298.7 & 0.72 & 0.15 & 0.59 \\
\hline
\end{tabular}

${ }^{a}$ From $\mathrm{N}_{2}$ absorption measurements (BET method). ${ }^{\mathrm{b}}$ From $\mathrm{N}_{2}$ absorption measurements (t-plot). ${ }^{\mathrm{c}}$ From $\mathrm{N}_{2}$ absorption measurements (BJH method).

Figure 4 presents the $\mathrm{NH}_{3}$-TPD profiles of the catalysts. In general, a lower temperature desorption at $150 \sim 300{ }^{\circ} \mathrm{C}$ and a higher one at $350 \sim 550{ }^{\circ} \mathrm{C}$ were detected, which were assigned to the weak and strong acid sites, respectively. Moreover, the desorption peaks of both strong and weak acid sites of HZSM-5-C, HZSM-N and HZSM-5-S shifted to higher temperatures compared to that of other catalysts. This indicated that the acidity of these samples was enhanced. The acid amounts calculated from the $\mathrm{NH}_{3}$-TPD profiles were listed in Table 3. It can be seen from this table that the addition of CMC-Na, $\mathrm{NaCl}$ and SA could significantly increase the amount of weak and strong acid sites of the catalyst, while PEG-10000 and KH-560 had little effect on it. It was believed that the acidity of HZSM-5 is mainly influence by the content and distribution of aluminum. The increase in acid amount might be caused by $\mathrm{Na}^{+}$and crystalline size. $\mathrm{Na}^{+}$led to the framework aluminum to the sinusoidal channel and straight channel [32]. In addition, the increase of silicon hydroxyl with smaller crystalline size also resulted in the increase of acid amount on the surface of the synthesized HZSM-5 [33]. On the other hand, although the composites of aluminum and silicon were the same in the synthesized gel, the additives would influence the inter-reaction of them and lead to the differences in $\mathrm{Si} / \mathrm{Al}$ ratio. This was also confirmed by the Si/Al ratio obtained by ICP-OES listed in Table 3, which shows that a larger $\mathrm{Si} / \mathrm{Al}$ ratio exhibited lower acid amounts.

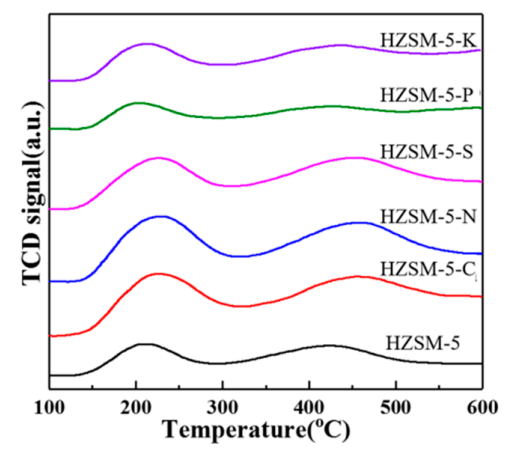

Figure 4. $\mathrm{NH}_{3}$-TPD images of synthesized HZSM-5 zeolites. 
Table 3. Distribution of acid sites and $\mathrm{SiO}_{2} / \mathrm{Al}_{2} \mathrm{O}_{3}$ ratio of the catalyst.

\begin{tabular}{ccccc}
\hline Catalysts & Total Acid $(\mathbf{m m o l} / \mathbf{g})$ & Weak Acid $(\mathbf{m m o l} / \mathbf{g})$ & Strong Acid $(\mathbf{m m o l} / \mathbf{g})$ & $\mathbf{S i O}_{2} / \mathbf{A l}_{\mathbf{2}} \mathbf{O}_{\mathbf{3}}(\mathbf{m o l} \%)$ \\
\hline HZSM-5 & 0.42 & 0.15 & 0.27 & 66.4 \\
HZSM-5-C & 0.86 & 0.34 & 0.52 & 54.9 \\
HZSM-5-N & 0.92 & 0.37 & 0.55 & 56.4 \\
HZSM-5-S & 1.24 & 0.44 & 0.80 & 50.3 \\
HZSM-5-P & 0.31 & 0.12 & 0.19 & 70.3 \\
HZSM-5-K & 0.52 & 0.19 & 0.33 & 63.7 \\
\hline
\end{tabular}

\subsubsection{Catalytic Performance of the n-HZSM-5 Catalysts}

According to the glycerin aromatization reaction in fixed-bed and production analysis methods in our previous study [34,35], the catalytic performance of the catalysts were evaluated. The yields and distributions of different aromatics are shown in Figure 5. As shown in the figure, the product distribution obtained by all the catalysts presented a similar tendency, where Xylene dominated and then toluene. The catalyst prepared with additives mainly influenced the content of xylene of the product, and the fractions of it with all these catalysts decreased compared with HZSM-5. In addition, the content of $\mathrm{C}_{9}{ }^{+}$increased obviously, especially that catalyzed by HZSM-5-P and HZSM-5-K. As the BTX mainly transformed from the dealkylation of $\mathrm{C}_{9}{ }^{+}$, the smaller crystalline particle (HZSM-5-C, HZSM-5-N and HZSM-5-S) and the mesoporous in the crystalline particle (HZSM-5-P and HZSM-5-K) made the $\mathrm{C}_{9+}$ easier to diffused from the catalyst, which led to the increase in $\mathrm{C}_{9}{ }^{+}$components. It was also found that the yields of total aromatics increased in the reactions catalyzed by HZSM-5-C, HZSM-5-N and HZSM-5-S. According to the proposed reaction pathway by Sikarin Tamiyakul et al. [9] and the acid amount results in Table 3, it can be concluded that a reasonable higher acid amounts improved the formation of aromatics. Among all catalysts, n-HZSM-5-S that has the highest acid amount shown in Table 3, showed the best performance on total aromatic yield (from $22 \%$ by HZSM- 5 to $35 \%$ ).

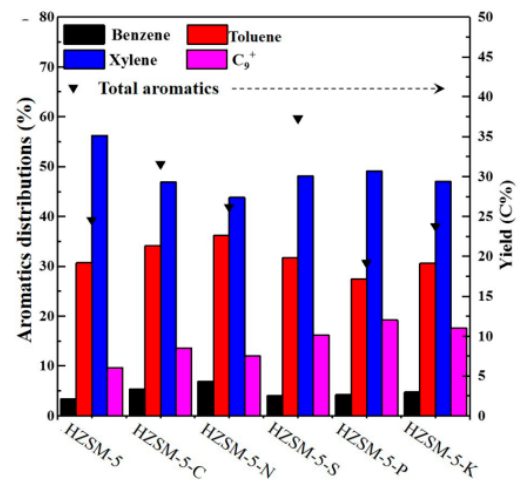

Figure 5. The yields and distribution of aromatics obtained by HZSM-5 zeolites synthesized with different additives.

The total carbon yields of BTX with different catalysts are shown in Figure 6. It can be seen that the yields of BTX presented an increased tendency firstly then became relatively steady and finally decreased rapidly (to yield $<10 \%$ ), which indicated the activation, stable catalyzing and deactivation process of the catalyst. the yields of BTX and the life of the catalyst were both promoted by the catalyst preparing additives. Typically, the highest yields obtained by HZSM-5-S and HZSM-5-N increased $\sim 50 \%$ compared to that by HZSM- 5 . It was believed that the more acid sites led to the higher yield of BTX, thus, the HZSM-5-C, HZSM-5-S and HZSM-5-N achieved higher BTX yields. At the same time, the catalyst life was doubled. The longest catalyst life was HZSM-5-K which was prolonged by about three times compared to HZSM-5. This proved that smaller crystal size and mesoporous could solve some diffusion problems and reduce coking, which could prolong the catalyst life. However, Combined with the results in Table 3 and Figure 5, less acid sites and larger pore size of n-HZSM-5-K 
made it non-beneficial to obtain BTX. Therefore, n-HZSM-5-S was chosen as the best catalyst and studied in the following effects of metal-modified work.

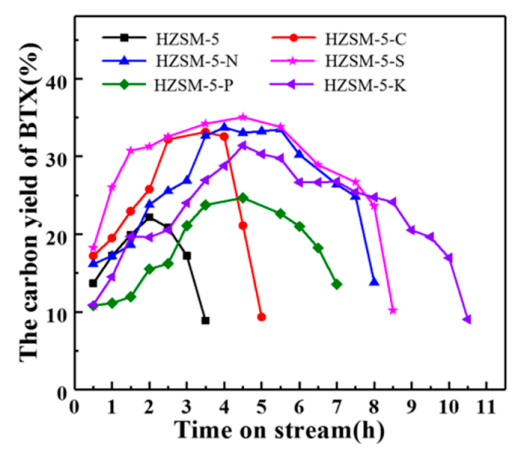

Figure 6. The total carbon yield of BTX obtained by HZSM-5 zeolites synthesized with different additives.

\subsection{Effects of the Metals}

\subsubsection{Characterization of the Modified n-HZSM-5 Catalysts}

According to the catalytic performance presented above, HZSM-5-S was chosen for further metal-modification studies. The catalyst prepared was denoted as [M]-HZSM-5-S, where M represented the metals added. Due to the preparation methods, the XRD patterns of the modified catalyst were almost the same as the bare ones. Meanwhile, the $\mathrm{N}_{2}$ adsorption and $\mathrm{NH}_{3}-\mathrm{TPD}$ profiles all showed similar tendency as Figures 3 and 4, which was in accordance with the literature [35]. Thus, only the physical properties and acidic amounts were provided, as shown in Table 4. Combined with Table 2, it can be seen that BET surface of the catalysts decreased slightly with the modification of the metal, while the volume of mesopores increased. This might be attributed to the intergranular mesoporous by incorporation of metal species introduced, demonstrating that metals have been incorporated into the framework of HZSM-5. Compared to the properties of HZSM-5-S shown in Table 3, the strong acid amount decreased obviously while the weak acid amount was almost unchanged with the introduction of metals. This may be caused by the metal species incorporated being replaced by parts of the conventional acid sites and forming some new acid sites.

Table 4. Physical properties and acids amounts of the [M, Al]-H-S catalysts.

\begin{tabular}{cccccccc}
\hline Catalysts & $\begin{array}{c}\mathrm{S}_{\text {BET }} \mathbf{a} \\
\left(\mathbf{m}^{2} / \mathbf{g}\right)\end{array}$ & $\begin{array}{c}\mathbf{S}_{\text {micro }} \mathbf{b} \\
\left(\mathbf{m}^{2} / \mathbf{g}\right)\end{array}$ & $\begin{array}{c}\mathbf{V}_{\text {micro }} \mathbf{b} \\
(\mathbf{m L} / \mathbf{g})\end{array}$ & $\begin{array}{c}\mathbf{V}_{\text {meso }} \mathbf{c} \\
(\mathbf{m L} / \mathbf{g})\end{array}$ & $\begin{array}{c}\text { Total Acid } \\
(\mathbf{m m o l} / \mathbf{g})\end{array}$ & $\begin{array}{c}\text { Weak Acid } \\
(\mathbf{m m o l} / \mathbf{g})\end{array}$ & $\begin{array}{c}\text { Strong Acid } \\
(\mathbf{m m o l} / \mathbf{g})\end{array}$ \\
\hline [Sn]-HZSM-5-S & 384.0 & 193.9 & 0.10 & 0.52 & 0.88 & 0.42 & 0.46 \\
[Zr]-HZSM-5-S & 376.6 & 203.1 & 0.11 & 0.46 & 1.02 & 0.41 & 0.61 \\
[Mn]-HZSM-5-S & 391.5 & 198.0 & 0.11 & 0.49 & 1.09 & 0.43 & 0.67 \\
[Cd]-HZSM-5-S & 386.2 & 205.4 & 0.11 & 0.61 & 1.11 & 0.42 & 0.69 \\
[Zn]-HZSM-5-S & 384.4 & 186.8 & 0.10 & 0.77 & 1.14 & 0.42 & 0.72 \\
\hline
\end{tabular}

\subsubsection{Catalytic Performance of Modified [M]-HZSM-5-S}

The product distributions and yields of BTX for aromatization of glycerol obtained by [M]-HZSM-5-S are shown in Figure 7. As presented in Figure 7A, compared with that obtained by HZSM-5-S, the fraction of xylene and $\mathrm{C}_{9}{ }^{+}$obtained by [Sn]-HZSM-5-S increased while the fraction of benzene and toluene decreased. However, the fractions of benzene and toluene were all increased with Zr, Mn, Cd and Zn-modified HZSM-5-S. This might be attributed to the less acidic [Sn]-HZSM-5-S, which inhibited the decomposition and dealkylation of $\mathrm{C}_{9}{ }^{+}$. As shown in Figure 7B, the catalyst life of metal-modified HZSM-5-S had not much difference compared with t bare HZSM-5-S, indicating that the metal introduced did not destroy the microporous. The [Zn]-HZSM-5-S and [Cd]-HZSM-5-S 
showed higher BTX yields, and in which [Zn]-HZSM-5-S showed the highest yield in the initial stage (TOS within $5 \mathrm{~h}$ ). This was consistent with previous research which demonstrated that $\mathrm{Zn}$ species presented promoting effects for aromatization [36]. The results showed that the improvement in deoxygenation (Sn) [37], hydrogen transformation ( $\mathrm{Zr}$ ) [38] or oxidation (Mn) [39] efficiency have little effects on the catalyst life and BTX yield. The n-HZSM-5 itself presented a relevant catalytic performance without further modifications [36,40].
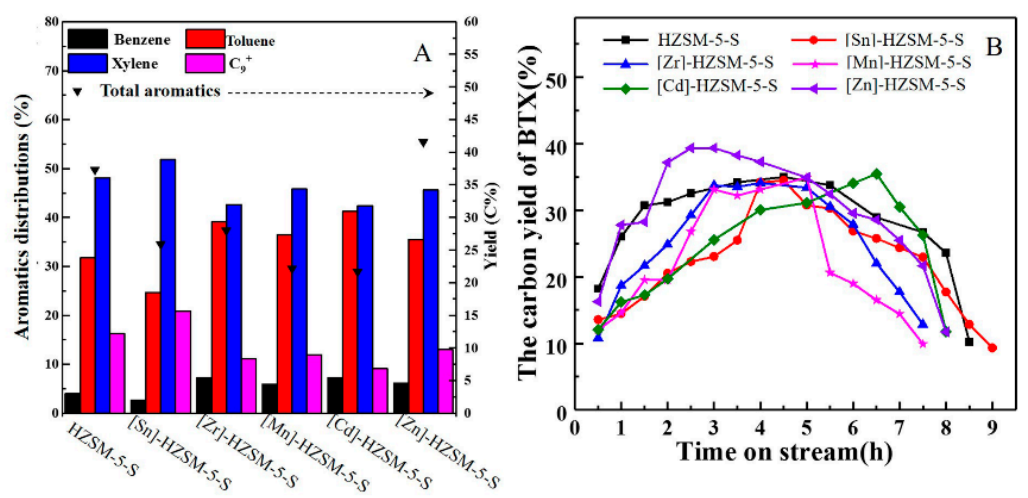

Figure 7. The yields and distribution of aromatics (A) and total carbon yield of BTX (B) obtained by [M]-HZSM-5-S.

\section{Materials and Methods}

\subsection{Materials}

Tetrapropylammonium hydroxide (TPAOH, $25 \mathrm{wt}$. \% aqueous solution), tetraethyl orthosilicate (TEOS, 28.4 wt. \% $\mathrm{SiO}_{2}$ ), aluminum isopropoxide (AIP, 24.7 wt. $\% \mathrm{Al}_{2} \mathrm{O}_{3}$ ), sodium alginate (SA, CP), $\mathrm{NaCl}$ (AR), $\mathrm{NH}_{4} \mathrm{Cl}$ (AR), Polyethylene glycol-1000 (PEG-1000, CP), methanol (AR) and glycerol (AR) were purchased from Sinopharm Chemical Reagent Co., Ltd, China. carboxymethylcellulose sodium (CMC-Na, $\mathrm{CP}$ ) and $\gamma$-(2,3-epoxypropoxy)propytrimethoxysilane (KH-560, $\mathrm{CP}$ ) were purchased from Shanghai Aladdin Bio-Chem Technology Co., Ltd, China. All the reagent were directly used without any further purification.

\subsection{Catalysts Preparation and Characterization}

The n-HZSM-5 were synthesized by hydrothermal method [35] with adding different additives. Typically, certain amounts of AIP was dissolved in TPAOH. Deionized water and TEOS were added into the obtained gel followed by stirring at $40{ }^{\circ} \mathrm{C}$ for $5 \mathrm{~h}$. The molar ratio of the composites in the above gel was $100 \mathrm{SiO}_{2}: 1 \mathrm{Al}_{2} \mathrm{O}_{3}: 25 \mathrm{TPAOH}: 2000 \mathrm{H}_{2} \mathrm{O}$. Additives were added in the gel with a ratio of $0.009 \mathrm{~g} / \mathrm{g}$ gel and maintained stirring at $40{ }^{\circ} \mathrm{C}$ for another $24 \mathrm{~h}$. Then the mixture was transferred into a Teflon-lined autoclave for static crystallization at $170^{\circ} \mathrm{C}$ for $24 \mathrm{~h}$. After cooling to room temperature, the precipitate was filtered and washed with deionized water, followed by calcinated at $550{ }^{\circ} \mathrm{C}$ in air for $5 \mathrm{~h}$. Finally, the HZSM- 5 was obtained by three times of ion-exchange between the as-prepared zeolites with $\mathrm{NH}_{4} \mathrm{Cl}$ aqueous solution $(1.0 \mathrm{~mol} / \mathrm{L})$ at $80^{\circ} \mathrm{C}$ for $8 \mathrm{~h}$, then dried at $80^{\circ} \mathrm{C}$ overnight and calcinated at $550{ }^{\circ} \mathrm{C}$ in air for $5 \mathrm{~h}$. The catalyst prepared with CMC-Na, NaCl, SA, PEG-10000 and KH-560 were denoted as HZSM-5-C, HZSM-5-N, HZSM-5-S, HZSM-5-P and HZSM-5-K, respectively. Bare HZSM- 5 was prepared as the same procedure without the addition of additives.

For the preparation of metal modified catalysts, the metal salts were added in the synthesize gel before crystallization. The molar ratio of metal salts and $\mathrm{Al}_{2} \mathrm{O}_{3}$ were kept at 0.25:1 [35].

X-ray diffraction (XRD) data were collected on a Rigaku Ultima IV instrument with $\mathrm{Cu} \mathrm{K} \alpha$ radiation $(\lambda=0.15406 \mathrm{~nm})$ at $40 \mathrm{kV}$ and $20 \mathrm{~mA}$; the range of the scan was $5 \sim 50^{\circ}$. Transmission electron microscopy (TEM) images were obtained with a FEI Tecnai G2 20 instrument operating with an accelerating voltage of $120 \mathrm{kV}$. Temperature-programmed desorption of ammonia $\left(\mathrm{NH}_{3}-\mathrm{TPD}\right)$ was 
conducted with a Xianquan TP-5076 automated adsorption system with an online thermal conductivity detector (TCD). The Si and Al contents were measured by inductively coupled plasma optical emission spectrometer (ICP-OES) on a Varian 720-ES instrument.

$\mathrm{N}_{2}$ adsorption analysis was obtained on a 3H-2000PS1 (BeiShiDe Instrument Company) specific area and pore size analysis instrument. The samples were degassed at $200{ }^{\circ} \mathrm{C}$ for $5 \mathrm{~h}$ under vacuum prior to the analysis and the specific surface areas were determined by multi-point BET method.

\subsection{Catalytic Reaction Procedure}

The catalytic aromatization of glycerol was conducted in an experimental scale fixed-bed reactor reported in our previous work [34,35]. According to the previous studies, $1.2 \mathrm{~g}$ of catalyst with a size of $40 \sim 60$ mesh $(0.30 \mathrm{~mm}<\mathrm{d}<0.45 \mathrm{~mm})$ was packed in the stainless-steel reactor (inner diameter: $8 \mathrm{~mm}$ ). The reactor was heated to $400{ }^{\circ} \mathrm{C}$ and kept for $1 \mathrm{~h}$ under a $\mathrm{N}_{2}$ flow of $30 \mathrm{~mL} / \mathrm{min}$. Then, glycerol dissolved in methanol solution (40 wt. \%) was pumped into the reactor with a weight hourly space velocity (WHSV) of $0.96 \mathrm{~h}^{-1}$ associated with preheated to $290^{\circ} \mathrm{C}$. The liquid products were collect by condensation and analyzed by gas chromatograph (GC-7890, Shanghai Techcomp Ltd) equipped with a FID detector and a capillary column (SE-30, $30 \mathrm{~m} \times 0.25 \mathrm{~mm}$ ). Chlorobenzene was used as the internal standard. As presented in our previous studies, since glycerol and methanol were totally converted in each case, carbon yield was used to characterize the catalytic efficiency. The yields were calculated with the following formula [35]:

$$
\text { Yield } \%=\frac{M_{\mathrm{i}}}{M_{\mathrm{in}}} \times 100 \%
$$

where $M_{\mathrm{in}}$ was the moles of carbon in the feedstock. $M_{\mathrm{i}}$ was the moles of carbon in specific product.

\section{Conclusions}

In this paper, n-HZSM- 5 was prepared by the addition of different additives in a synthesized gel. The effects of the additives were evaluated by characterization and the catalytic activities in the production of aromatics from glycerol. The results showed that all the n-HZSM- 5 catalysts synthesized had better catalytic efficiency and life than conventional HZSM-5. The addition of CMC-Na, $\mathrm{NaCl}$ and SA was beneficial for the formation of smaller sized HZSM-5, and SA was the best among them. At the same time, the acid amounts of the catalysts were also promoted by them, which led to the higher catalytic activities for BTX. Despite the relatively lower acid amount, KH-560, which introduced more mesoporous, made the catalyst more stable in the catalytic system. Based on the SA-derived n-HZSM-5, the effects of metal modification were evaluated. The results showed that the BTX yields could be improved by $\mathrm{Zn}$ and $\mathrm{Cd}$. However, the introduction of metals has little effect on the catalyst life.

Author Contributions: W.X. and L.G. conceived and designed the experiments; W.X. performed the experiments and analysis; W.X. mainly wrote the paper and all authors revised the paper. W.X., L.G., G.X. have read the final version of the manuscript.

Funding: The research was funded by National Natural Science Foundation of China (No. 21406034 \& 21676054), Jiangsu Planned Projects for Postdoctoral Research Funds (No. 2018K013A) and Talents Introduction Foundation of Nanjing Institute of Technology (YKJ201936).

Conflicts of Interest: The authors declare no conflict of interest.

\section{References}

1. Ardi, M.S.; Aroua, M.K.; Hashim, N.A. Progress, prospect and challenges in glycerol purification process: A review. Renew. Sust. Energ. Rev. 2015, 42, 1164-1173. [CrossRef]

2. Monteiro, M.R.; Kugelmeier, C.L.; Pinheiro, R.S.; Batalha, M.O.; Cesar, A.D. Glycerol from biodiesel production: Technological paths for sustainability. Renew. Sust. Energ. Rev. 2018, 88, 109-122. [CrossRef] 
3. Xiao, Y.; Xiao, G.M.; Varma, A. A universal procedure for crude glycerol purification from different feedstocks in biodiesel production: experimental and simulation study. Ind. Eng. Chem. Res. 2013, 52, 14291-14296. [CrossRef]

4. Rekha, V.; Raju, N.; Sumana, C.; Lingaiah, N. Continuous hydrogenolysis of glycerol to 1,2-propanediol over Bi-metallic Ni-Ag supported on gamma- $\mathrm{Al}_{2} \mathrm{O}_{3}$ Catalysts. Catal. Lett. 2017, 147, 1441-1452. [CrossRef]

5. Viswanadham, B.; Nagaraju, N.; Rohitha, C.N.; Vishwanathan, V.; Chary, K.V.R. Synthesis, characterization and catalytic dehydration of glycerol to acrolein over phosphotungstic acid supported Y-zeolite catalysts. Catal. Lett. 2018, 148, 397-406. [CrossRef]

6. Xiao, W.Y.; Wang, F.; Xiao, G.M. Performance of hierarchical HZSM-5 zeolites prepared by NaOH treatments in the aromatization of glycerol. RSC Adv. 2015, 5, 63697-63704. [CrossRef]

7. Wang, F.; Zhou, M.X.; Yang, X.H.; Gao, L.J.; Xiao, G.M. The effect of hierarchical pore architecture on one-step catalytic aromatization of glycerol: Reaction routes and catalytic performances. Mol. Catal. 2017, 432, 144-154. [CrossRef]

8. Jang, H.S.; Bae, K.; Shin, M.; Kim, S.M.; Kim, C.U.; Suh, Y.W. Aromatization of glycerol/alcohol mixtures over zeolite H-ZSM-5. Fuel 2014, 134, 439-447. [CrossRef]

9. Tamiyakul, S.; Ubolcharoen, W.; Tungasmita, D.N.; Jongpatiwut, S. Conversion of glycerol to aromatic hydrocarbons over Zn-promoted HZSM-5 catalysts. Catal. Today 2015, 256, 325-335. [CrossRef]

10. Hoang, T.Q.; Zhu, X.L.; Sooknoi, T.; Resasco, D.E.; Mallinson, R.G. A comparison of the reactivities of propanal and propylene on HZSM-5. J. Catal. 2010, 271, 201-208. [CrossRef]

11. Zhang, B.; Zhong, Z.P.; Chen, P.; Ruan, R. Microwave-assisted catalytic fast pyrolysis of biomass for bio-oil production using chemical vapor deposition modified HZSM-5 catalyst. Bioresour. Technol. 2015, 197, 79-84. [CrossRef] [PubMed]

12. Conte, M.; Lopez-Sanchez, J.A.; He, Q.; Morgan, D.J.; Ryabenkova, Y.; Bartley, J.K.; Carley, A.F.; Taylor, S.H.; Kiely, C.J.; Khalid, K.; et al. Modified zeolite ZSM-5 for the methanol to aromatics reaction. Catal. Sci. Technol. 2012, 2, 105-112. [CrossRef]

13. Hoang, T.Q.; Zhu, X.L.; Danuthai, T.; Lobban, L.L.; Resasco, D.E.; Mallinson, R.G. Conversion of glycerol to alkyl-aromatics over zeolites. Energy Fuels 2010, 24, 3804-3809. [CrossRef]

14. Zhang, G.Q.; Bai, T.; Chen, T.F.; Fan, W.T.; Zhang, X. Conversion of methanol to light aromatics on Zn-modified nano-HZSM-5 zeolite catalysts. Ind. Eng. Chem. Res. 2014, 53, 14932-14940. [CrossRef]

15. Wang, F.; Kang, X.; Zhou, M.X.; Yang, X.H.; Gao, L.J.; Xiao, G.M. Sn and Zn modified HZSM-5 for one-step catalytic upgrading of glycerol to value-added aromatics: Synergistic combination of impregnated $\mathrm{Sn}$ particles, ALD introduced ZnO film and HZSM-5 zeolite. Appl. Catal. A-Gen. 2017, 539, 80-89. [CrossRef]

16. Austin, D.; Wang, A.G.; He, P.; Qian, H.; Zeng, H.B.; Song, H. Catalytic valorization of biomass derived glycerol under methane: Effect of catalyst synthesis method. Fuel 2018, 216, 218-226. [CrossRef]

17. Qi, R.Y.; Fu, T.J.; Wan, W.L.; Li, Z. Pore fabrication of nano-ZSM-5 zeolite by internal desilication and its influence on the methanol to hydrocarbon reaction. Fuel. Process. Technol. 2017, 155, 191-199. [CrossRef]

18. Wan, Z.J.; Wu, W.; Li, G.; Wang, C.F.; Yang, H.; Zhang, D.K. Effect of $\mathrm{SiO}_{2} / \mathrm{Al}_{2} \mathrm{O}_{3}$ ratio on the performance of nanocrystal ZSM-5 zeolite catalysts in methanol to gasoline conversion. Appl. Catal. A-Gen. 2016, 523, 312-320. [CrossRef]

19. Wang, F.; Chu, X.Z.; Zhu, F.X.; Li, Q.Q.; Wu, F.Y.; Liu, B.H. Study on catalytic performance and deactivation behavior of HZSM-5 in aromatization of glycerol. Energy Technol. 2018, 6, 2238-2246. [CrossRef]

20. Zhang, K.; Liu, Y.Q.; Zhao, J.C.; Liu, C.G. Hierarchical porous ZSM-5 zeolite synthesized by in situ zeolitization and its coke deposition resistance in aromatization reaction. Chin. J. Chem. 2012, 30, 597-603. [CrossRef]

21. Chu, S.; Guo, X.C.; Li, J.; Bai, J.; Mu, X.D.; Yang, L.N. Synthesis of $\mathrm{Ga}_{2} \mathrm{O}_{3} / \mathrm{HZSM-5@cubic} \mathrm{ordered} \mathrm{mesoporous}$ $\mathrm{SiO}_{2}$ with template Pluronic F127 to improve its catalytic performance in the aromatization of methanol. J. Porous Mater. 2017, 24, 1069-1078. [CrossRef]

22. Groen, J.C.; Jansen, J.C.; Moulijn, J.A.; Perez-Ramirez, J. Optimal aluminum-assisted mesoporosity development in MFI zeolites by desilication. J. Phys. Chem. B 2004, 108, 13062-13065. [CrossRef]

23. Hoang, T.Q.; Zhu, X.L.; Lobban, L.L.; Resasco, D.E.; Mallinson, R.G. Effects of HZSM-5 crystallite size on stability and alkyl-aromatics product distribution from conversion of propanal. Catal. Commun. 2010, 11, 977-981. [CrossRef] 
24. Jia, Y.M.; Wang, J.W.; Zhang, K.; Feng, W.; Liu, S.B.; Ding, C.M.; Liu, P. Nanocrystallite self-assembled hierarchical ZSM-5 zeolite microsphere for methanol to aromatics. Microporous Mesoporous Mater. 2017, 247, 103-115. [CrossRef]

25. Yang, L.Z.; Liu, Z.Y.; Liu, Z.; Peng, W.Y.; Liu, Y.Q.; Liu, C.G. Correlation between H-ZSM-5 crystal size and catalytic performance in the methanol-to-aromatics reaction. Chin. J. Catal. 2017, 38, 683-690. [CrossRef]

26. Zhao, Y.; Liu, J.X.; He, N.; Liu, C.Y.; Guo, H.C. A comparison on the hydrothermal stability of nano-sized H-ZSM-5 zeolite modified by ammonium dihydrogen phosphate and trimethylphosphate. Catal. Lett. 2019, 149, 2169-2179. [CrossRef]

27. Fu, T.J.; Chang, J.W.; Shao, J.A.; Li, Z. Fabrication of a nano-sized ZSM-5 zeolite with intercrystalline mesopores for conversion of methanol to gasoline. J. Energy Chem. 2017, 26, 139-146. [CrossRef]

28. Wu, S.H.; Zhang, W.W.; Jia, S.Y.; Liu, Y.; Ran, J.Y.; Ren, H.T.; Hou, J.W. Novel pathway for the synthesis of monodisperse MCM-41 nanospheres with different particle size distributions. Mater. Lett. 2013, 98, 138-141. [CrossRef]

29. Tian, H.F.; Zhang, Z.Z.; Chang, H.; Ma, X.X. Catalytic performance of imidazole modified HZSM-5 for methanol to aromatics reaction. J. Energy Chem. 2017, 26, 574-583. [CrossRef]

30. Tao, H.X.; Yang, H.; Liu, X.H.; Ren, J.W.; Wang, Y.Q.; Lu, G.Z. Highly stable hierarchical ZSM-5 zeolite with intra- and inter-crystalline porous structures. Chem. Eng. J. 2013, 225, 686-694. [CrossRef]

31. Demadis, K.D.; Mavredaki, E.; Somara, M. Additive-driven dissolution enhancement of colloidal Silica. 1. basic principles and relevance to water treatment. Ind. Eng. Chem. Res. 2011, 50, 12587-12595. [CrossRef]

32. Yokoi, T.; Mochizuki, H.; Namba, S.; Kondo, J.N.; Tatsumi, T. Control of the Al distribution in the framework of ZSM-5 zeolite and its evaluation by solid-state NMR technique and catalytic properties. J. Phys. Chem. C 2015, 119, 15303-15315. [CrossRef]

33. Erofeev, V.I.; Adyaeva, L.V.; Ryabova, N.V. Effect of high-temperature steam treatment of high-silica zeolites of the ZSM-5 type on their acidity and selectivity of formation of lower olefins from straight-run naphthas. Russ. J. Appl. Chem. 2003, 76, 95-98. [CrossRef]

34. Pan, D.H.; Song, X.H.; Yang, X.H.; Gao, L.J.; Wei, R.P.; Zhang, J.; Xiao, G.M. Efficient and selective conversion of methanol to para-xylene over stable $\mathrm{H}[\mathrm{Zn}, \mathrm{Al}] \mathrm{ZSM}-5 / \mathrm{SiO}_{2}$ composite catalyst. Appl. Catal. A-Gen. 2018, 557, 15-24. [CrossRef]

35. Yang, X.H.; Wang, F.; Wei, R.P.; Li, S.; Wu, Y.F.; Shen, P.X.; Wang, H.Z.; Gao, L.J.; Xiao, G.M. Synergy effect between hierarchical structured and Sn-modified H[Sn, Al]ZSM-5 zeolites on the catalysts for glycerol aromatization. Microporous Mesoporous Mater. 2018, 257, 154-161. [CrossRef]

36. Wang, F.; Xiao, W.Y.; Gao, L.J.; Xiao, G.M. Enhanced performance of glycerol to aromatics over Sn-containing HZSM-5 zeolites. RSC Adv. 2016, 6, 42984-42993. [CrossRef]

37. Veses, A.; Puertolas, B.; Lopez, J.M.; Callen, M.S.; Solsona, B.; Garcia, T. Promoting deoxygenation of bio-Oil by metal-loaded hierarchical ZSM-5 zeolites. ACS Sustain. Chem. Eng. 2016, 4, 1653-1660. [CrossRef]

38. El Morsi, A.K.; Shokry, S.A. Transformation of n-octane into aromatic hydrocarbon over ZSM-5 zeolites. Pet. Sci. Technol. 2000, 18, 1195-1207. [CrossRef]

39. Meng, Y.T.; Genuino, H.C.; Kuo, C.H.; Huang, H.; Chen, S.Y.; Zhang, L.C.; Rossi, A.; Suib, S.L. One-step hydrothermal synthesis of manganese-containing MFI-type zeolite, Mn-ZSM-5, characterization, and catalytic oxidation of hydrocarbons. J. Am. Chem. Soc. 2013, 135, 8594-8605. [CrossRef]

40. Pan, D.H.; Xu, S.Q.; Miao, Y.N.; Xu, N.N.; Wang, H.Z.; Song, X.H.; Gao, L.J.; Xiao, G.M. A highly active and stable Zn@C/HZSM-5 catalyst using Zn@C derived from ZIF-8 as a template for conversion of glycerol to aromatics. Catal. Sci. Technol. 2019, 9, 739-752. [CrossRef]

(C) 2019 by the authors. Licensee MDPI, Basel, Switzerland. This article is an open access article distributed under the terms and conditions of the Creative Commons Attribution (CC BY) license (http://creativecommons.org/licenses/by/4.0/). 